\title{
Police Departments as Institutionalized Organizations
}

Police departments can be described from many perspectives, but one useful perspective is an institutional one. Institutional theory has been widely used in the study of private- and public-sector organizations generally, and it has been applied previously to police departments. We sketch that perspective here. We did not set out to test propositions drawn from institutional theory, nor do we purport to offer tests of that theory in the chapters that follow. But we believe that institutional theory can in large measure account for our findings, and we adopted this perspective because we think that it is very useful in understanding the dynamics of police administration in general and the management of procedural justice in particular. ${ }^{1}$ Thus we explain what it means for an organization to be institutionalized, and we describe at some length relevant parts of the institutional environment of police departments in the United States. Then we turn to the study departments, and describe them in terms of their institutional environments.

\section{PERSPECTIVES ON POLICE ORGANIZATIONS}

The technology of policing-that is, how the work gets done-is an intensive one, with choices about how to proceed made in any one case as events unfold. Policing thus requires the exercise of discretion, and that discretion is exercised in its most palpable forms on the street and by the lowest-ranking members of police organizations. The task environment of policing is heterogeneous, ambiguous, and turbulent, with countless contingencies that bear on officers' choices, factors to be weighed even though their meaning and implications are not clear, and subject to a great deal of uncertainty surrounding the consequences of alternative courses 
of police action (Thompson 1967). What police officers should do in most of the situations that they handle on a day-to-day basis cannot be specified in policy and procedure manuals. "You can't go by the book," as police are wont to say.

The task environment and the technology of police work have far-reaching implications for how police work can be managed. Police departments are what James Q. Wilson (1989) describes as "coping organizations"-those organizations whose managers cannot easily observe their subordinates' operations or assess the value of those operations for achieving desired social outcomes. The managers of such organizations are not powerless, but they are sharply constrained in their capacity to direct what the organization does and how it is done. Police officers work for the most part outside of direct supervision, they perform work that is rife with situational contingencies, and information about what they do and the circumstances under which they do it is normally recorded by the officers themselves. The consequences or effects of what police do are subject to a host of influences other than police action, so managers cannot infer from observed or documented consequences what officers actually did; even scientifically structured evaluations of police intervention cannot provide definitive evidence about the effectiveness of what police do, and scientific evaluations are seldom performed.

Police departments are also what Michael Lipsky (1980) calls "street-level bureaucracies," whose front-line workers exercise wide discretion in their interactions with the agency's clients. Street-level bureaucracies are "people-processing" organizations (Prottas 1978). Teachers, social workers, police officers, and others are all street-level bureaucrats, and they must cope with some common conditions of work: chronically inadequate resources, including time and information; vague, ambiguous, and sometimes conflicting organizational goals; and an inability to control the pace or outcomes of their work. Consequently, according to Lipsky, street-level bureaucrats develop patterns of practice that are in some respects dysfunctional for the organization's clients but enable the workers to cope: they husband resources; they routinize their processing of cases; they reconceptualize their jobs in order to reduce the discrepancy between the ideal and the achievable; and they reconceptualize their clientele. These systemic forces have impacts that are largely beyond the capacity of managers to control.

Michael Brown (1981) argues that the police bureaucracy exerts control over only the more mundane aspects of police work, such as the timeliness and neatness of officers' reports, and that the substantive exercise of police discretion is controlled-insofar as it is controlled at all-by the peer group, or the police culture. We often think of the police culture as a set of outlooks that are widely shared among police officers: strong loyalty to co-workers, an "us vs. them" mentality; suspiciousness and cynicism; an occupational focus on crime control and law enforcement, and a correspondingly derisive regard for order maintenance and service functions; and a willingness to bend or break rules governing the use of force 
or search and seizure. Moreover, the police culture has long been recognized as an impediment to bureaucratic control, and the paramount value of loyalty manifests itself in a norm of mutual cover-ups of bureaucratic (and legal) transgressions. Elizabeth Reuss-Ianni (1983) describes street cop culture and its codes, including "don't give up another cop," as antithetical to management cop culture.

If this was ever an accurate characterization of an entire occupational group, it is no longer (Herbert 1998; Paoline 2004; Paoline, Myers, and Worden 2000; Paoline and Terrill 2014), but police culture remains an important consideration. Brown's portrayal of police culture is simpler and it may be timeless. He asserts that the police culture is comprised of two core values: loyalty and individualism. As other accounts of police culture hold, loyalty to co-workers-backing them up in the face of the threats to their safety, and honoring their accomplishments in the context of a police bureaucracy that is "punishment-centered"-is an occupationally universal value, owing mainly to the danger in the occupational environment. Individualism allows officers to practice their own styles and apply their own priorities, and to do so without second-guessing. Individualism allows for heterogeneity among officers in their conceptions of the police role, in their degree of cynicism, in their respect for restrictions on their authority, and in their "operational styles" (Brown 1981). Research has repeatedly found such heterogeneity, rather than a monolithic police culture. So it is that Brown's description of police culture can be reconciled with the research that has found not a single occupational culture but rather multiple subcultures. This more delimited and accurate rendition of police culture has important implications for how tenuously bureaucratic controls are connected to the discretionary choices that together comprise the delivery of police services. The culture legitimizes street-level individuality in doing police work, and the nature of the work makes it very difficult to apply bureaucratic controls.

Front-line supervisors can affect some types of officers' behavior, but not all supervisors are created equal, and the impact of supervision on behavior will be attenuated or amplified by individual supervisors' own orientations and styles (Engel 2001, 2002). William Ker Muir Jr. (1977) explains how supervisors can be instrumental in their subordinates' professional growth and moral renewal if they are actively engaged in developing their subordinates' skills and judgment. But such forms of supervision have not been normal in law enforcement (Brown 1981; Engel 2001, 2002; Van Maanen 1983); the potential impact of supervision probably remains unfulfilled in many cases. Immediate supervisors are caught in the middle, between management and the street, and, as Brown observed, "the pressures for loyalty and solidarity are refracted throughout the police bureaucracy" (1981, 90), with norms that prohibit second-guessing and micro-management. Many supervisors keep their priorities limited and expectations low (Van Maanen 1983), and they may not even be comprehended by their subordinates (Engel and Worden 2003). 
Furthermore, many efforts to change the way that street-level policing is performed are subject to a process of interpretation by the officers whose behavior is the target of the change, a process known in the study of organizations as "sensemaking." Officers' interpretations will not always conform with those of police executives. Some police subcultures will be receptive to a reform proposed by management, such as community policing, and others will tend to resist, based on the compatibility of the reform (as officers make sense of it) with officers' own occupational values and attitudes.

\section{AN INSTITUTIONAL PERSPECTIVE}

Every organization is subject to the environments in which it operates, including a technical environment and an institutional environment. Technical environments are those in which the goods or services produced by an organization are exchanged, as in private markets, and that reward the effective and efficient production of those goods or services. Institutional environments, by contrast, contain requirements or expectations for the structure of an organization and reward the adoption of required or favored structures, not effective or efficient production as such.

Some types of organizations, such as manufacturing firms, operate in a welldeveloped technical environment, where production processes are well understood and a market establishes the value of the products, and a weak institutional environment. Other types of organizations operate in a weakly developed technical environment and a strong institutional environment. For these organizations, the technical environment provides a limited understanding of cause-and-effect relationships in the production technology, such that it may be hard to assess the technical performance of an organization or even to say what effective and efficient production is. But the institutional environment contains well-developed expectations or requirements for how the organization should be structured. These expectations are institutional "myths," or "idealized cultural accounts" of how an organization should operate (Hallett 2010). Structures are adopted and maintained, not because they have a well-established and well-understood utility in effective and efficient production, but rather because they are expected or demanded by external stakeholders, or "sovereigns," as markers of proper and/or professional operations. Thus, even if they do not serve to make the organization more effective or otherwise perform better, the structures serve to confer legitimacy: "a generalized perception or assumption that the actions of an entity are desirable, proper, or appropriate within some socially constructed system of norms, values, beliefs, and definitions" (Suchman 1995, 574).

Institutional pressures take several forms, and they may tend to yield a high degree of structural homogeneity among the organizations in an organizational 
"field" (DiMaggio and Powell 1983). Some such pressures are "coercive," such as statutory, regulatory, or judicial requirements or mandates, or widely shared cultural expectations. Other pressures arise from the structures and practices of other organizations in the same field that are perceived to be successful; the presumed virtues of those structures or practices make them appear worthy of emulating. Still other pressures stem from professional or occupational norms or standards. These various forces in an organizational field tend to produce institutional "isomorphism" of corresponding kinds-coercive, mimetic, and normative, respectivelysuch that organizations in a field tend to be structurally similar to one another. Conformity to these various demands and expectations is the price of legitimacy for organizations whose institutional environments are strong. Legitimation is achieved by an organization not through its technical performance but by meeting these environmental demands, that is, adopting structures and practices that institutional myths prescribe.

Police departments are particularly susceptible to forces in their institutional environments. By virtue of the nature of the work that they perform, police departments have:

- vague, ambiguous, conflicting goals;

- uncertain technologies for turning raw materials-people and their problemsinto valued outputs;

- great difficulty in monitoring the work of turning raw materials into outputs; and

- great difficulty in evaluating the effects of the work that is done.

As many have observed, technical performance by police organizations encompasses many dimensions. Moore (2002) identifies several dimensions of performance as part of the mission of police, including reducing crime and criminal victimization; holding offenders to account; reducing fear and enhancing a sense of security; regulating public spaces and traffic safety; and providing emergency medical and social services. In addition, the economy with which police operate, in terms of the expenditure of money and/or authority, is a basis for assessing police performance, so the efficient use of public resources and the fair and judicious use of police authority may be considered. Not all of these facets of the police mission are compatible with one another, as improving performance in one area (e.g., respecting civil liberties) may come at the expense of performance in another (e.g., crime control), and people inside and outside of the organization may not agree on the relative importance of those areas. Little information is available about the technical performance of the police, and to a large degree judgments about technical performance require inferences about causal relationships among police inputs, outputs, and outcomes that are embedded in larger systems of social and economic forces; even when police strategies or programs are subjected to scientific evaluations, inferences about the 
impacts of police interventions are subject to some doubt. These challenges weaken the technical environment of policing.

The institutional environment of policing is fairly well developed, however. Among the structures that police might adopt in order to conform to broad cultural expectations are "appropriate titles, uniforms, badges, and insignia indicating rank, department and assignment" (Crank and Langworthy 1992, 342-43). Indeed, even the Weberian bureaucracy in U.S. policing, dating from the Progressive era, is an organizational form that was adopted and maintained because it is expected by external stakeholders, as well as by many inside of policing, despite its questionable compatibility with the technical demands of police work (Brown 1981); the task environment and technology of policing is more compatible with a much less bureaucratic form of organization. But institutional forces compel police organizations to maintain a bureaucratic form - some would say a "presentational strategy" or façade (Manning 1977) — that includes thick books of policies and procedures and a quasi-military chain-of-command, which (at least partially) satisfies the public expectation of control over the exercise of police authority. The appropriateness of a bureaucratic form for police departments is largely taken for granted. In a police department that is institutionalized, then, structural features-the division of labor, the allocation of resources, and recruitment, selection, training, supervision and management practices - may be continued or changed based, not on their demonstrable technical utility, but rather on widespread suppositions about their value.

The range of actors whom we would consider sovereigns in police departments' institutional environment encompasses what Moore describes as the "authorizing environment," including "all those political actors or agents who have the formal power to review police department operations, or the informal power to influence those who do" $(2002,84)$. They include elected and appointed officials-mayors and city councilors, city managers, comptrollers, civil service commissions-as well as the representatives of interest groups and "watchdog" organizations (e.g., the American Civil Liberties Union), police unions, and the media. They also include other law enforcement organizations at higher levels of government, professional organizations (e.g., the International Association of Chiefs of Police) and accrediting bodies (such as the Commission on Accreditation for Law Enforcement Agencies), as well as actors with regulatory authority, e.g., the courts, and the Civil Rights Division of the Department of Justice. In the United States, most but not all of these sovereigns are local. These external stakeholders, whose support is required for the organization's survival and prosperity, are as hard-pressed as anyone is to ascertain what the organization does and the contribution that it makes to social outcomes. They tend to fall back on suppositions about how an organization should be structured, even if the structural prescriptions have not been tested and validated. The suppositions represent "ordinary knowledge" (Lindblom and 
Cohen 1979). To the degree that external stakeholders rely on such suppositions, the organization's legitimacy is determined, not by how well the work is actually performed, but by how closely the organization conforms to the expectations of its institutional environment.

The expectations of these various sovereigns need not and often do not agree with one another, and any one sovereign's expectations need not be internally consistent, making the institutional environment complex. Demands for community policing, for example, are not entirely compatible with demands for public accountability: pushing discretion down as much as possible to field supervisors and beat officers, and thereby unleashing the creativity of officers in addressing the many and varied problems that communities confront, is a prominent feature of community policing, but expanding officers' discretion is not entirely compatible with demands for public accountability and administrative rule-making, which tend to emphasize constraints on police discretion. An institutional environment of such complexity and, potentially, contradiction, has implications that we consider below.

We would add that to recognize the strength of the institutional environment of policing is not to hold that the technical environment is irrelevant or that police executives deliberately adopt structures merely for symbolic purposes. The adoption of structures that serve institutional purposes may also serve more conventional technical-rational purposes in an organization, and even if the structures serve only more symbolic purposes, for reasons that we discuss below, it does not follow that their adoption was an act of administrative duplicity.

Institutional myths may be incompatible with the requirements of the organization's tasks (as they are perceived by operators such as teachers or police officers), or with one another, creating the potential for structural conflict. One way that such conflict can be averted is through the "loose coupling" of structures with technical activities, which allows the continued performance of technical tasks without hindrance by structures that satisfy sovereigns' expectations but are not compatible with the work. Such buffering need not be by executive design. When the structures that police departments adopt are incompatible with one another, with previously existing structures that remain in use, or with the technical demands of the work itself, something has to give. Often, the "technical core"-in policing, that would be the street-level work of patrol officers or detectives-is, in effect, buffered from the structures with which the work is not compatible. We do not doubt that when police executives adopt new structures such as community policing or Compstat, they do so in good faith and for the intended instrumental benefits that they promise in accomplishing the work of the organization. Structural forces are more powerful than the wills and good intentions of police executives, however, and as the complexity of the organization's structure mirrors that of the institutional environment, with features that are incompatible with one 
another and with the technical core, loose coupling (or decoupling) can result. Technical performance that is loosely coupled (or decoupled) from structural reforms may not be readily detected, for the same conditions that make it difficult for sovereigns to judge technical performance make it difficult for managers to detect such loose coupling. Thus institutionalization stems from the nature of the work, not from managerial ineptitude or resistance (though some managers are inept and others have their own agendas).

In an organization whose goals are vague and ambiguous, whose operators work largely independently, and whose technical activities bear an uncertain relationship to organizational outcomes, structures are subject to interpretation-a process of "sensemaking" (Weick 1995; also see Bechky 2011; Hallett and Ventresca 2006; Sharma and Good 2013). Schools fit this description, as do police departments. Efforts to change such organizations require winning the "hearts and minds" of operators. The adoption of structures that are incompatible with work requirements may breed cynicism toward managers who are seen to engage in political posturing.

We pause here to note that legitimacy in the context of institutional theory certainly bears a resemblance to the constellation of outlooks that social psychologists have labeled legitimacy, but there are important differences. Institutional theory treats legitimacy as a property of organizations. Organizations can establish and maintain their legitimacy. Organizational legitimacy can be challenged or threatened. And organizations can lose legitimacy. An organization's legitimacy turns on perceptions and judgments by actors-sovereigns - in its environment, but its relationship to public attitudes is less proximate. We will return to these connections in the next chapter.

Research on policing provides a number of illustrations of institutionalization in addition to those mentioned above, and we briefly describe a few of these here, reserving more extended descriptions of others for discussion in conjunction with the institutional environment of U.S. policing a bit later. Consider, for one example, the Junction City Police Department (a pseudonym). When the department adopted a specialized gang unit, it was not because the department's chief perceived street gangs as a threat to the safety of Junction City (Katz 2001). It was a consequence of external pressure brought by segments of the community that saw gangs as a community problem warranting the formation of a specialized unit, and in spite of the chief's conviction that gangs were not a problem. The newly created gang unit, comprised of a sergeant and four investigators, represented a feature of the department's structure whose existence was owed not to the technical requirements of policing, but rather to the demands of powerful external constituencies for an organizational response of the expected form. The operation of the unit, in the absence of a serious gang problem toward which to direct their efforts, consisted first of public presentations and subsequently of forming partnerships with 
other, well-established units-such as homicide - thus gaining unit legitimacy through its association with reputable partners.

Another example involves training in drunk-driving enforcement (Mastrofski and Ritti 1996). Among six police agencies-two each of city police departments, township police departments, and state police troops - three exhibited a strong connection between training in enforcement against driving under the influence (DUI) and officers' actual enforcement practices, while three others did not. In the former, DUI enforcement activity was actively encouraged and rewarded; the training was tightly coupled to practice. In the latter, however, police management was not supportive of DUI enforcement; in two of those agencies, managers perceived that high levels of DUI enforcement conflicted with other organizational goals. DUI training served a purpose, but it was an institutional one, uncoupled from the work of enforcement. Consider one agency:

Township 2 has a well-developed institutional presentation of DUI enforcement, in which training is an important element. The local MADD chapter provided some incentive for addressing the DUI issue. . . . None of these, however-banquets, awards, donations of breath-testing equipment, and public education campaignswere tied to the actual work of making DUI arrests. DUI training was also part of the highly developed professional reputation cultivated by the leaders, based (for example) on being well-equipped, well-dressed, and client-oriented. (Mastrofski and Ritti 1996, 316)

Specialized training, which certainly can serve instrumental purposes when the subject of the training is reinforced by other organizational practices, can instead serve institutional purposes. The same might be said, more speculatively in the absence of empirical research, about other police training curricula. Stephen Mastrofski and R. Richard Ritti allow as how "a police brutality scandal . . generates pressures for reform, which leads to an extensive training program on race relations, less-than-lethal methods, and 'verbal judo"' (1996, 292).

One final example, for now, is a pro-arrest policy for spouse assault. In the 1980 s and 1990s, many police agencies adopted policies that mandate or encourage arrests for some types of domestic violence. Many factors contributed to the adoption of such policies: a grass-roots battered women's movement pressed for legislative changes that would facilitate or compel law enforcement to invoke the law against offenders (Ferraro 1989); the threat of litigation against police departments; recommendations by the Attorney General's Task Force on Family Violence; and the findings of the Minneapolis domestic violence experiment, which concluded that repeat violence was less likely when police made arrests (Sherman and Cohn 1989). Pro-arrest policies have increased the incidence of arrests in cases of spousal assault, though compliance by officers is only partial (Cross and Newbold 2010; Eitle 2005; Ferraro 1989; Hirschel et al. 2007; Jones and Belknap 1999). Evidence from replications of the Minneapolis experiment have cast doubts on the 
conclusions that were drawn from that study, but it is doubtful that many departments have abandoned pro-arrest policies, which are still expected by sovereigns.

\section{THE INSTITUTIONAL ENVIRONMENT OF POLICING}

Police departments across the United States have been subject to a number of environmental forces for change in the past twenty to thirty years, but as Mastrofski and James Willis (2010, 57) observe, "the core police patrol technology has remained essentially unchanged for decades." Notwithstanding the panoply of accoutrements that adorn an officer's belt and, increasingly, his/her patrol car, police work is now and has always been a human service occupation that is performed through direct interaction with people, and that relies mainly on verbal communication. Coercive authority is the occupational prerogative that makes a police force a unique domestic organization, but most of the functions that police perform, most of the time, turn on how they talk with and to people. These basic features of police work have not changed with the introduction of the radio, the vehicle, computers, or cell phones.

The stability of the basics of police work stands in contrast with changes in the institutional environment. Local officials and other constituencies, state officials, and federal officials have all exerted pressures on police departments. Some of the pressures conflict with one another. These environmental forces have led police officials to adopt structural forms that are widely considered desirable, even in the absence of clear connections to valued outputs or outcomes, but that may be and often are only loosely coupled with street-level practice. We would direct attention to three such forms that the institutional environment of U.S. policing has, in general, promoted: community policing; mechanisms of public accountability; and mechanisms of management accountability.

\section{Community Policing}

With roots in team policing and foot patrol, community policing had by the $1980 \mathrm{~s}$ emerged as a new strategy of policing. It includes establishing a new kind of relationship between police and communities and new practices in addressing the public's safety concerns. Police form partnerships with neighborhood groups and community agencies, seek and accept community input and influence on police priorities so that police address the concerns of the community, and foster more cooperative relationships between officers and community members. Officers make the acquaintance of community members and learn about neighborhood norms and concerns, and police address community problems through the practice of problem-oriented policing. Thus community policing calls for far-reaching structural and operational changes in police departments (Sparrow et al. 1990): establishing structures that facilitate community input and influence; forming 
partnerships with community agencies (e.g., sanitation, public works) through which community problems can be addressed; flattening the police hierarchy and decentralizing authority; providing for stable beat assignments for officers in order to inculcate attachments to and knowledge of communities; training officers in new practices; supervising and evaluating officers in new ways. Community policing is no programmatic "add-on" to existing organizational structures.

Community policing has enormous appeal to local constituencies, invoking images of "the friendly night watchman" who walks a beat and of a "community" in the sense of groups of like-minded individuals, living in urban areas, who share a common heritage, have similar values and norms, and share a common perception of social order" (Crank, 1994: 335-336). The adoption and implementation of community policing was given a major federal boost in 1994 with the enactment of the Violent Crime Control and Law Enforcement Act, Title I of which provided for grants to state and local police agencies that subsidized the hiring of new officers, so long as the grantee agencies adopted some version of community policing. So it was that multiple forces in the environment of police agencies led (or pushed) them in the direction of this strategic innovation.

Research on the implementation of community policing, however, has generally found organizational innovations of a more limited, programmatic nature. A national survey conducted by the Police Foundation in 1993 found that only one-third of the respondents agreed that structural change was necessary for community policing, and almost 40 percent did not agree that "community policing requires major changes of organizational policies, goals, or mission statements" (Wycoff 1994, 32). Jeffrey A. Roth et al. (2004) report on a succession of agency surveys, in 1995, 1998, and 2000, in which they asked agencies about each of ten organizational practices that are associated with the implementation of community policing, such as establishing neighborhood patrol boundaries, alternative response methods to free up time for proactive work, and revising employee evaluations. In 2000, their survey showed that the percentages of even large agencies that indicated that they had adopted these practices ranged from about 40 to 80 . A previous survey and site visits led them to observe that "funding conditioned expressly on community policing implementation, coupled with substantial peer pressure to embrace this model of policing, has also led a substantial number of law enforcement agencies to stretch the definition of community policing-to include under its umbrella traditional quick-fix enforcement actions, draconian zero tolerance policies, long established crime prevention programs, and citizen advisory councils that are clearly only advisory" (Roth 2000, 237).

Other research has recounted resistance to community policing among rankand-file police, whose hearts and minds have been difficult to win over to a new definition of the police role, new ways to relate to the community, and new practices. Some officers who are more service-minded, and who may have been practicing a 
community-oriented style on their own, are quite receptive to the implementation of community policing. Eugene A. Paoline III (2004) describes “peacekeepers," for example, as having (relatively) positive attitudes toward the community and a role orientation that emphasizes order maintenance. But Paoline also finds a group he labels "traditionalists," whose outlooks resemble those of the conventionally described police culture: they prize crime-fighting and denigrate order maintenance, they endorse aggressive policing tactics and resent legal restrictions, and they are skeptical about citizen cooperation. More generally, we can surmise that officers are likely to embrace the practice of community policing to the degree to which it is consistent with their occupational outlooks, and consequently the implementation of community policing will face resistance in many though not all quarters (see Skogan 2008; Wood et al. 2004).

Problem-oriented policing (POP) is a key element of community policing, which focuses attention on constellations of related incidents- "problems" - and the conditions that contribute to them, on the plausible assumption that if one or more of the conditions can be changed, the problem may be ameliorated or even solved entirely. POP is contrasted with incident-driven policing, which provides only for handling incidents one by one, as police typically do when they respond to 911 and other calls for service. POP requires not only a recognition that incidents are related to one another, but also analysis of conditions that contribute to the problem and that are within the power of police (and/or their partners) to alter. Moreover, POP is thought to be most effective when the search for responses that might alter the identified conditions is not limited to the enforcement of the penal law. Whether the scope of the targeted problem is wide or narrow, POP calls for a reorientation from incidents or cases-an orientation to which police become accustomed by their experience-to problems, and also from provable, concrete facts and evidence to more abstract patterns based on data that are not always accurate or complete.

Experience with POP teaches us that its practice is not easily achieved (see Capowich et al. 1994; Cordner and Biebel 2005; Police Executive Research Forum 2000; Sampson and Scott 2000). The popular SARA model of the POP processScanning, Analysis, Response, and Assessment-makes analysis central to the practice of POP (Eck and Spelman 1987; see also Tilley 2003); analysis, as the SARA model highlights, is the bridge from problem identification to the formulation of possible solutions. The problem-analysis triangle is a tool in whose use many officers have been trained, and it highlights the role of analysis in problem-solving. The problem-analysis triangle encourages those doing problem analysis to consider three components that all problems have in common: an offender, a victim, and a location. Each of these may afford some leverage on the problem, though police attention has traditionally focused on the offender. Situational crime prevention, by contrast, focuses on features of the location, changes in which may reduce the 
opportunities for offending. Similarly, changes in the behavior of would-be victims may reduce the opportunities for offending. Studies of POP have found that police officers tend to focus on narrowly defined problems; skip over or give short shrift to the analysis that supports problem-solving; and rely on conventional, enforcement-based responses. Instead of POP, then, research has found more narrowly conceived "problem-solving" (Clarke 1998).

Even when community policing is implemented as a strategic reform, as it was in Chicago as much as (and probably more than) it was in any other city, it is fragile. There, after a decade of community policing and in the wake of a mediagenerated "crime scare" that coincided with the selection of a new superintendent of police, the new administration prioritized tough enforcement.

The new chief ... reorganized and refocused the department on guns, gangs, and homicides. Soon commitment to the department's community policing program withered. Most districts lost their community-policing managers, lieutenants who were instead put in charge of flying squads. All of the department's slack resources were rounded up to staff them. Police hoping to get ahead organizationally gravitated toward crackdown units, for they are the focus of the top brass. Headquarters accountability reviews, which used to include community-policing activities and goals, were scaled back dramatically to make time for discussion of homicide patterns. Activities that better fit a recentralized management structure driven by recorded crime have become what matters. The only thing that protects the shell of the program that remains is that it was politically infeasible to shut it down, so deeply are the beatoriented parts of community policing woven into the political and organizational life of the city's neighborhoods. There it lurks, waiting perhaps to be resurrected when a crisis of legitimacy again haunts the police, and they have to rediscover community policing in order to rebuild again their credibility with the community. (Skogan 2008, 33)

There is much to commend community policing as a police strategy, but the adoption and implementation of community policing has confronted the challenge of coupling its organizational structures to street-level practice.

\section{Public Accountability}

Police brutality and other forms of police misconduct have been recurring issues at both the local and national levels for decades, and over the past forty years the country has seen the proliferation of one presumptive remedy: citizen oversight. This typically takes the form of what are widely known as civilian review boards, which are authorized to oversee the processing of citizens' allegations of police misconduct. Citizen oversight might provide for the involvement of civilians, rather than sworn officers, in the receipt of complaints, in monitoring or assessing police investigations of alleged misconduct, or even in conducting their own "external" investigations pursuant to citizen complaints. The establishment of citizen 
oversight in the 1980s and 1990s has been characterized as a "national movement" (Walker 2001). City after city adopted some version of citizen oversight, usually in the aftermath of a widely publicized incident of what was perceived as police brutality, and in response to local demands. The popularity of citizen oversight appears to rest on a deep-seated distrust of the willingness of the police to police themselves, that is, to conduct thorough investigations of complaints against fellow officers, or even to faithfully accept complaints when citizens seek to file them. Police departments did not, in general, welcome the establishment of citizen oversight. The push for citizen oversight is a force in the institutional environment to which departments have had to adapt.

However, there is no evidence that citizen oversight alters patterns of police behavior or performance. Indeed, there is no evidence that citizen oversight has impacts even on more proximate outcomes: the rate at which the allegations in citizen complaints are substantiated or "sustained" by investigation; or complainants' satisfaction with the complaint review process (DeAngelis 2009; Perez 1994; Sviridoff and McElroy 1989; Walker 2001; also see Livingston 2004; National Research Council 2004). There is, however, good reason to believe (and some evidence) that, at the margin, citizen oversight elevates the confidence of the public (if not of individual complainants) in the integrity of the complaint review process (Kerstetter and Rasinski 1994; Skolnick and Fyfe 1993; Worden and Becker 2015). Citizen oversight thus serves the purpose of promoting police legitimacy, but it appears to be decoupled from the technical core of policing.

Citizen oversight of police is not the only structural demand in the institutional environment that relates to public accountability. In the past twenty years, the Civil Rights Division of the Department of Justice (DOJ) has used authority with which it was endowed by the 1994 Crime Act to investigate allegations of a "pattern or practice" of civil rights violations by local police departments. DOJ can pursue (or threaten) litigation, one frequent outcome of which has been a settlement in the form of either a consent decree or a memorandum of agreement that stipulates the adoption of a series of organizational reforms (Harmon 2009; Walker 2003). Beginning with the Pittsburgh police in 1997, DOJ has investigated and reached agreements with numerous agencies, including the Cincinnati Police Department, the Los Angeles Police Department, and the New Jersey State Police. Court-appointed monitors oversee the implementation of the reforms, and the decree is lifted only when the agreed-upon reforms are implemented to the court's satisfaction. Even when the investigation does not lead to an agreement, DOJ may issue a "technical assistance letter" that includes a series of recommendations for organizational change. The reforms that DOJ mandates through consent decrees (or recommends in letters) tend to emphasize the establishment or strengthening of citizen oversight, the implementation of early intervention systems, and policy development. These mandates purportedly are based on "best practices," but in 
fact they are based on the kinds of suppositions that we described above, lacking empirical validation of their effectiveness. We have already considered citizen oversight.

Early intervention (EI) systems (also known as early warning systems) synthesize and use management information about police outputs that are "risk-related" (Bobb and staff 2009) to identify "problem officers," whose performance displays symptoms of misconduct, and to intervene as early in the emerging pattern as possible with training or counseling, thereby preventing further misconduct. Given the well-documented concentration of citizen complaints and use-of-force incidents among a small fraction of a police force, EI systems rest on a compelling logic. Several studies of EI systems have produced results that suggest that they reduce the incidence of complaints and the use of force, but the designs of these studies were weak, with either no control group or a nonequivalent control group; one recent study, with a much stronger design, found that one agency's EI system was ineffective in reducing complaints, the use of force, or secondary arrests, but had the unintended consequence of inhibiting officers' initiative (Worden et al. 2013; also see Lersch et al. 2006). An assessment of Pittsburgh's EI system, implemented as part of the consent decree there, found that even officers who had not been subject to EI system intervention reported feeling such inhibitions, and supervisors complained about the demands for paperwork that left them with less time to supervise officers directly, in the field (Davis et al. 2005). Thus, as promising as the concept may be, the jury is still out on the utility of EI systems as they are currently designed and operated. Furthermore, EI systems are not infrequently only loosely coupled with practice, as some recent investigative journalism has found (Kelly 2016).

DOJ lawyers have also required or recommended the formulation or further development of policy and procedure, especially concerning the use of force by police. Such administrative rule-making can be effective under some circumstances in regulating police behavior (Prottas 1978; Walker 1993; Worden 1995). James Fyfe (1979) demonstrated, for example, that the administrative rules established by the New York City Police Department to govern the use of deadly force were effective in reducing police-involved shootings; Fyfe's research $(1979,1988)$ also makes it clear, however, that the effectiveness of the rules turned on their enforcement, which was effected by a firearms-discharge review process, and which was feasible because, for the most part, the use of deadly force by police is difficult to conceal. For another example, as noted above, policies mandating or encouraging officers to make arrests when they have probable cause in cases of spousal assault have increased the incidence of such arrests. The documentation that comes with officers' compliance with these rules facilitates their enforcement by supervisors, but even so, given officers' near monopoly on information about cases in which arrests are not made, compliance is only partial at best, (Cross and Newbold 2010; 
Ferraro 1989). Generally, we might hypothesize that the lower the visibility of the discretionary action that is the subject of administrative rules, the less able the department is to enforce the rule and the lower the rate of officers' compliance will be. Little of the discretionary behavior in which officers engage is readily visible to supervisors and managers (Goldstein 1960), and Michael Brown (1981) concluded that bureaucratic controls did not by and large extend to the substantive exercise of police discretion.

A national survey of law enforcement agencies revealed a dizzying array of permutations with respect to the placement of particular forms of force relative to others on a use-of-force continuum, and no one policy emerged as "best" in an intensive examination of the use of force in eight police departments, with neither bivariate nor multivariate analysis detecting "consistent policy effects" (Terrill, Paoline, and Ingram 2012, 198-99). However, in an analysis of three of the eight departments, whose policies varied in their restrictiveness, Terrill and Paoline (2016) find that officers in the department (Charlotte-Mecklenburg) with the most restrictive policy used less force than those in the departments (Albuquerque and Colorado Springs) with less restrictive policies. We think it quite likely that the impact of use-of-force policies will be contingent on the will of administrators and supervisors to enforce the policies. Terrill and Paoline note that "perhaps Charlotte-Mecklenburg supervisors were more active with respect to emphasizing use of force policy, thereby giving policy on paper more 'substance' so to speak. Alternatively, perhaps Colorado Springs and Albuquerque supervisors were more lax in terms of policy guidance (e.g. 'rubber stamping' force reports)" (2016: 19). In other words, policies designed to guide and constrain officers' discretion in the use of less-lethal force can be coupled with practice, so long as police managers and supervisors enforce their department's policy; lax supervision and management concerning the use of force is liable to leave policy loosely coupled with officers' practices. One success story of change in this regard appears to be Cincinnati, whose officers' rates of using force declined following reforms to which the police department agreed in a settlement with DOJ in 2002 (Schatmeier 2013; Chanin 2015); we consider the experience of Cincinnati further in chapter 10.

Demands for public accountability in the institutional environment of policing have promoted the adoption of particular organizational structures-citizen oversight, early intervention systems, and administrative rules governing the use of force - that have little or no demonstrated efficacy in regulating officers' behavior, and are in many or most instances only loosely coupled to street-level performance. But their adoption by police departments is taken as a signal of good practice, and the Department of Justice has been one external stakeholder demanding the adoption of these structures, with the threat of litigation. Use-of-force policies may hold more promise, with tighter coupling possible so long as managers and supervisors implement the policies. 


\section{Management Accountability}

Compstat is an administrative innovation introduced as part of the "reengineering" of the New York City Police Department wrought by Commissioner William Bratton in the mid-199os (Bratton 1998, esp. chap. 14). Seeking to make the commanders of NYPD's seventy-five precincts the engines of crime-reduction initiatives, Commissioner Bratton gave precinct commanders more authority to develop operational plans and to allocate their resources accordingly, holding them accountable through Compstat for using their authority to achieve crime-reduction results. Compstat originated in meetings with borough and precinct commanders at which their performance could be assessed, justified, and critiqued, with information on that performance available to all present; the information about crime, initially available in a book of weekly crime totals, became increasingly detailed and rich, so that what started as "crime meetings" evolved into "computerstatistics" meetings.

NYPD's Compstat was-correctly or not-credited with the dramatic decline in New York City's crime rate through the latter half of the 1990s, and consequently it has been widely emulated by police agencies across the United States and the world. In 1996, Compstat was recognized with an "Innovations in American Government" award by the Ford Foundation and Harvard's Kennedy School of Government. By 2000, one third of the 515 American police agencies with 100 or more sworn personnel had adopted a Compstat-like program, and an additional one quarter were planning such a program (Weisburd et al. 2003). Compstat has also been adopted by other types of public agencies, and by city mayors and even state governors. Compstat can be an organizational mechanism that serves, first, to direct attention to important police outcomes-crime, disorder, fear of crime, quality of life, citizen satisfaction-and, second, to stimulate the formulation and implementation of tactical and strategic operations directed toward those outcomes (Moore 2002). Like POP, Compstat is data-driven and outcome-oriented. Using timely, accurate data is one of its principles, and the selection of effective tactics on the basis of those data is another. "Relentless follow-up and assessment" is also based on data about police action and outcomes. Compstat requires the development of an analytic capacity, and when it operates properly, it also serves to exploit the potential of crime and intelligence analysis more completely, for it is a mechanism that can stimulate the translation of analytic products into crimereduction operations.

But the replication of NYPD's Compstat in other agencies has not always adhered to the same principles, and it has not proved to be effective in prompting precinct commanders or their subordinates to engage in innovative problem-solving; it has not proved effective even in holding commanders accountable for outcomes (Behn 2008; Silverman 2006; Weisburd et al. 2003; Willis et al. 2003, 2007). Compstat in NYPD would not have been so effective as an accountability tool were it 
not for the larger reengineering of the department, including "structural, operational, and strategic reconfigurations" (Silverman 2006, 273). One of the keys was the recognition that precinct commanders could be held accountable for reducing crime only if they were granted greater latitude to formulate crime-reduction initiatives and to allocate resources accordingly. Grafting Compstat onto a police department's preexisting organizational arrangements is unlikely to produce similarly salutary effects; Compstat would then be liable to be no more than loosely coupled with either management or tactical operations. The adoption and continued operation of Compstat could serve the organization's interests, enhancing its legitimacy, but without stimulating the kinds of operations that have been credited with New York's crime decline.

That is exactly what was found in a study of three police departments in which the adoption of Compstat amounted to "mimetic isomorphism," which is to say that they simply copied "other organizations that have received recognition and support for appearing effective" (Willis et al. 2007, 152). Compstat was loosely coupled to operations: in none of the departments did accountability extend down past the precinct or district commanders, with no "efforts to get the rank-and-file to respond to the direction of middle managers," and consequently Compstat "did not strengthen control over lower-ranking officers who continued to exercise the same high level of discretion long recognized as a characteristic of police work" (165-66). Commanders succeeded in the context of the Compstat meetings by being prepared with facts and figures to respond to the chief's questions, and not by devising and implementing effective crime-reduction strategies. More generally, it appears that Compstat reforms tended to strengthen the existing top-down chain of command, rather than stimulating innovative problem-solving- "changing everything so that everything can remain the same" (Weisburd et al. 2006).

\section{Complexity and Conflict}

The institutional environment is complex, and its demands on police departments are not all mutually compatible. Pushing discretion down as much as possible to precinct commanders or, even further, to field supervisors and beat officers, and thereby unleashing the creativity of officers in addressing the many and varied problems that communities confront, is a prominent feature of community policing. But expanding officers' discretion is not entirely compatible with demands for public accountability and administrative rule-making, which tend to emphasize constraints on police discretion. And as Wesley Skogan's (2008) observations about numbers-driven policing in Chicago illustrate, community policing and management accountability can be difficult to reconcile, especially since so much of what community policing involves and seeks to accomplish is not readily subject to quantitative measurement. This kind of complexity in the institutional environment of policing helps to explain how it is that day-to-day police work might be 
decoupled from or loosely coupled with the structures that agencies adopt: when the structures that police departments adopt conflict with one another or with the nature of the work, something has to give. When something gives, however, it need not give way entirely: we need not and should not suppose that technicalrational considerations are absent or that organizational structures-even those adopted to satisfy demands of the institutional environment-have no impact on technical performance. But insofar as street-level practices are loosely coupled to organizational structures, the impacts of the structures on practices are attenuated.

\section{Procedural Justice and Police Legitimacy}

As police executives have acknowledged the significance of legitimacy, and the role of procedural justice in improving legitimacy, they have responded to an emerging force in their institutional environment. Summarizing research on policing, the National Research Council drew attention to these issues in its volume titled Fairness and Effectiveness in Policing (2004), an entire chapter of which was devoted to police legitimacy. DOJ has supported the development of training in procedural justice through the Office of Community Oriented Policing Services (COPS), and it has supported research on procedural justice and legitimacy (including the inquiry on which we report here) through the National Institute of Justice. The International Association of Chiefs of Police (IACP) has held sessions on procedural justice and legitimacy at its annual conference. The Police Executive Research Forum, a well-known notfor-profit membership organization of police officials, recently published two reports on legitimacy and procedural justice (Fischer 2014a, 2014b). As we noted in chapter 1, the DOJ-funded National Initiative for Building Community Trust and Justice is designed to serve as a demonstration project, piloting in six police departments structures that promise to enhance public trust in local police. The President's Task Force on 21st Century Policing highlighted measures to enhance procedural justice, and, with it, police legitimacy, in its recommendations and implementation guide.

Legitimacy and procedural justice have not supplanted the other forces in the institutional environment, however, and the procedural justice model is not entirely compatible with them. The procedural justice model will not be compatible with Compstat-like mechanisms unless procedural justice can be regularly quantified as a performance measure with sufficient validity and reliability for it to be incorporated into a management-accountability system. Procedural justice may be celebrated, in ceremonial fashion, as an important consideration in the practice of policing, but it is liable to assume the position of an only symbolic feature of police administration and not a set of principles that are infused into the technical core of police departments and manifested in officers' day-to-day interactions with citizens. The implementation of the procedural justice model 
may also confront some of the same obstacles that so challenged the implementation of community policing: winning the hearts and minds of officers and field supervisors. It is subject to the same process of street-level interpretation, or sensemaking, as community policing, and it is likely to be accepted by some officers and resisted by others. Street-level procedural justice probably cannot be achieved through the formulation and promulgation of administrative rules, since the procedural justice that officers demonstrate in their behavior is of decidedly low visibility, and rules governing procedurally just action would be difficult to enforce. Procedural justice is arguably more a matter of "workmanship" than "legality" (Bittner 1983), and putting standards of workmanship into place confronts legal, bureaucratic, union, and other practical issues.

\section{THE INSTITUTIONAL ENVIRONMENTS OF POLICING IN SCHENECTADY AND SYRACUSE}

We have sketched the institutional perspective on organizations, and selected features of the institutional environment of U.S. policing, in order to better understand the findings of our research on Schenectady and Syracuse, whose police departments accommodated survey-based measures of procedural justice into their management-accountability systems. We turn now to a description of these departments as settings for this research, attending particularly to the rationale for conducting the research in these two departments, and to the elements of their institutional environments that are important for understanding the contexts in which research results were generated.

The Schenectady and Syracuse Police Departments are mid-sized agencies, and in this respect they resemble many other departments; among the respondents to the 2007 Law Enforcement Management and Administrative Statistics (LEMAS) survey, one can find nearly 500 agencies with 100 to 500 sworn, full-time employees, but only 89 agencies with more than 500 sworn personnel, about half of which have more than 1,00o sworn. No sample of two agencies could possibly be representative of American municipal police departments, but insofar as the external validity of empirical findings about the dynamics of organization and management is circumscribed by the size of the studied departments, Schenectady and Syracuse are propitious sites for research. Moreover, an examination of two departments rather than one allows us to ascertain the extent to which the findings are idiosyncratic to a single department.

The two cities are similar in a number of respects. They are both rustbelt cities that are coping with demographic and economic shifts that have strained governmental capacities with greater demands for services and an eroding tax base. The populations are comparable in their racial and ethnic composition. Both cities have fairly high rates of violent crime, especially for cities of their size. 
The two departments also share a number of similarities. Their sworn ranks are disproportionately white, relative to the cities' populations, with limited representation of women. However, both departments had, at the beginning and through most of the project, a black chief executive; Syracuse had a female deputy chief. These facts may have a bearing on perceptions of the departments' legitimacy.

We had a relationship with each department before we approached either chief about his department's participation in the project. In Syracuse, we had worked since late 2004 as the research partner to a criminal justice task force that included the police department. We had worked as a research partner to the Schenectady Police Department since 2004. Both departments afforded the proximity that was required for ongoing data collection and appearance at Compstat meetings. Both chiefs were, as we anticipated, receptive to the project, based on their avowed interest in ensuring high-quality police service to the citizenry. Finally, the two departments had contrasting public images. Schenectady's had a poor image acquired through years of extraordinary turmoil and scandal. Syracuse's had what we take to be a fairly typical image, free of the taint of extraordinary mishaps. Accordingly, we presumed that there would be a degree of contrast with respect to levels of respect and trust among those they serve.

\section{Schenectady}

According to 2010 Census figures, the city of Schenectady has 66,135 residents and is comprised of ten distinct neighborhoods across its ten square miles. Nearly one-quarter (24.4 percent) of the population was under the age of 18; 61 percent of it was white, 20 percent, African American, 10.5 percent, Hispanic or Latino, and 3.6 percent, Asian. The proportion of Schenectady's population living in poverty (22.5 percent) was half again that of the nation (15 percent). The city's violent crime rate exceeds the average of the largest U.S. cities: in 2010, Schenectady's violent crime rate of 1117.7 per 100, o0o population was 183 percent higher than that of cities of comparable size (394.6) and 57 percent higher than that of the largest U.S. cities. The rates are as striking with respect to homicide. In 2010, the homicide rate in Schenectady was 13.2, which was more than three times greater than in cities of comparable size (3.9), and 47 percent higher than that of the largest cities.

The Schenectady Police Department had a sworn strength of 160 and an actual strength of 158 in 2007, 114 of whom were uniformed and regularly assigned to patrol duties. ${ }^{2}$ Most (94.3 percent) of the sworn personnel were white, 3.8 percent were black, and 1.9 percent were Hispanic; 5.1 percent were female. Schenectady's chief of police is appointed by the mayor but enjoys civil service status and protection. The chief who in 2010 agreed to participate in this project was first appointed in 2008 and retired at the beginning of 2013. The assistant chief of the Field Services Bureau oversees uniformed patrol, which is organized into three 
platoons, each commanded by a lieutenant, with officers deployed across eight patrol zones.

Like many U.S. police departments, Schenectady had established a community policing unit, to which 24 of its 158 officers were assigned, though it had no formal, written community-policing plan. The unit was part of the Field Services Bureau. Training in community policing was provided to all officers through either recruit or in-service training. The department encourages officers to conduct SARA-guided problem-solving projects, but it does not include officers' work on those projects in personnel evaluations.

Citizen oversight exists in Schenectady, though it is not prominent. In 2002, after two years of deliberations, the Civilian Police Review Board (CPRB) replaced the Police Objective Review Commission. Modeled on the citizen-oversight mechanism in neighboring Albany, the CPRB is comprised of eleven members appointed by the mayor to serve two-year terms. The CPRB reviews the investigations of citizen complaints by police internal affairs investigators, and in cases involving allegations of excessive force or (other) civil rights violations, the board may hire an independent investigator to review the police investigation. The board may return a complaint to internal affairs for further investigation or reevaluation, and when it is satisfied with the investigation, it renders findings of approved, disapproved, or unable to be determined.

The department initiated Compstat in late 2010, following nearly a year of deliberation about its design and preparation. Thus Compstat had been operational for just a year at the outset of this project. Schenectady's Compstat provides for monthly meetings, at each of which units of both the Field Services Bureau (patrol and traffic) and the Investigative Services Bureau (detectives) are subject to review. The three platoon commanders report individually on platoon performance, so each platoon is examined separately. Statistics on crime and enforcement, citywide and at the platoon level, are displayed as appropriate. We further describe Schenectady's Compstat in chapter 8, but suffice it to say here that although it unmistakably makes each platoon commander individually responsible for his or her platoon's performance, it is not-and was not intended to be-punitive. Whereas management accountability requires the application of formal or informal sanctions when performance falls short of expectations, Schenectady's Compstat does not provide for it. More generally, the operation of Compstat in Schenectady bears a strong resemblance to that of Compstat in the three departments described by Willis et al. 2007.

The Schenectady Police Department has a long and troubled history of unfavorable portrayal in the media and scandals involving the misbehavior of its members. In 2001, after years of complaints by citizens about the use of excessive force and mounting pressure by civil rights activists to address the problem, the department became the subject of a probe by the DOJ Civil Rights Division. The 
New York Times recounted some of the incidents that were symptomatic of the problem, one of which was this:

Suspecting that David Sampson was up to no good but having no proof, the two white police officers chose instead to take him for a ride that summer's evening in 1999. A long, long ride. They drove in silence, ignoring the young black man's questions as their patrol car crossed the city limits and continued 11 miles deep into the countryside's enveloping dusk. 'I kept asking them 'Where am I going?' over and over, 15, 16 times," Mr. Sampson, 29, said recently. "I was really scared." They came to a stop on a gravel road. While his partner stayed behind the wheel, Officer Richard Barnett later recalled, he removed their passenger's boots, tossed them into the surrounding trees and told Mr. Sampson "to get out and have a nice walk back to Schenectady." Then the car, emblazoned with the name of the Schenectady Police Department, sped into the darkness, its back seat emptied. This is Schenectady, where the police do things differently. Officer Barnett later said under oath that it was "common practice for a lot of midnight shifts taking intoxicated people out of the city." It was called "relocation," he said, and had been the source of great amusement among officers. (Barry 2001)

"Relocation" was later characterized as an official unwritten policy to DOJ investigators. The officers involved in the Sampson incident became the subjects of an FBI investigation, but not because of their practice of relocation; one of them admitted in a plea agreement that "he and his partner once paid an informer with crack that they had just extorted from a drug dealer" (Barry 2001). Other officers were also prosecuted on similar allegations; one of them had tipped off an informer to police surveillance.

In March 2003, DOJ issued a "technical assistance" letter (Cutlar 2003). Based on its review of the department's written policies and procedures, interviews with officers at various levels of the department's hierarchy, and ride-alongs with officers, DOJ identified a number of deficiencies and made a number of recommendations. Those recommendations for the most part followed the template described above: further development of policies governing the use of force; strengthening the procedures for complaint intake and investigation (since Schenectady already had a citizen oversight body); and establishing an early warning system, including the information infrastructure that such a system requires (including use-of-force reporting). More specifically, and for example, DOJ recommended that "the SPD adopt a progression of force model that describes the available force options on a continuum . . . that relates the appropriate officer response to the specific actions of a suspect." For another example, DOJ recommended that "every officer in the department be required to accept a written complaint presented by a citizen," and that written policy should specify the types of complaints that can be investigated by the subject officer's unit and those that are investigated by internal affairs. DOJ also recommended the formulation of a "comprehensive risk management plan," including specific supervisory responsibilities, in addition to an early warning system. 
The turnaround was slow, and the local media continued to report with some regularity on officers' driving while intoxicated, engaging in domestic assaults, "cooping" (sleeping on duty), and worse. A veteran detective of the department pled guilty to possessing drugs and tampering with evidence from the vice squad locker, and as part of a plea agreement, he was sentenced to four years in state prison and one year of probation. Following an investigation of the vice squad, a number of vice detectives were reassigned or retired and the assistant chief over the unit was ultimately reassigned. "For the Schenectady Police Department, a department with a well-documented history of controversy and scandal, this latest news seemed to most of us almost unfathomable," the mayor told a press conference (Schenectady 2007). In a later article articulating allegations of an officer collecting overtime pay while inside an apartment complex instead of on patrol, Schenectady City Councilman Gary McCarthy said: "It's human nature to make mistakes, but this just seems so institutionalized" (Nelson 2009). In 2009, a former Schenectady chief and his wife were arrested and pleaded guilty to possession of a controlled substance and their role in a drug ring. It was found that the ex-chief, his wife, and his stepson were part of a group of "some two dozen people who funneled large quantities of cocaine and heroin from Long Island and Manhattan onto the streets of Schenectady" (Nelson 2010).

Due to the widespread disrepute of the department and its members, the mayor of Schenectady is reported to have considered in 2009 multiple options for the future of City's policing; these options included, but were not limited to, martial law, disbanding the police department, contracting out to the New York State Police or county sheriff's, or using the National Guard. The mayor did not in fact take any of the aforementioned routes; instead he was able to start removing problem officers and enacted a zero-tolerance policy for the officers. A retired superintendent of the New York State Police was appointed commissioner in 2007, with greater authority than the chief had to fix discipline. By August of 2010 the City had removed eight officers from its force that year.

If residents of Schenectady still hear of their city's police officers being apprehended or investigated for driving while intoxicated, assault, or domestic issues, they also hear of them having to face consequences and being held accountable for their actions. In late 2012, DOJ ended its investigation, declaring that the department was not in violation of federal law, and citing its adoption of some of DOJ's 2003 recommendations (Nelson 2013). We may reasonably consider that chapter of the department's history to be closed, but memories of it may linger, potentially tarnishing the image of the department as a whole among the city's residents and throughout the entire region.

It might not be an exaggeration to say that in 2009, the Schenectady Police Department suffered a crisis of legitimacy, with the city's mayor publicly contemplating dismantling it. Even allowing for the possibility that the mayor's public posture 
was struck as a move calculated to gain some leverage in collective bargaining negotiations, it is probably a measure of how far the department's stock with its sovereigns had fallen that the mayor would openly speculate, for public consumption, about the wisdom of abolishing the police department.

\section{Syracuse}

The city of Syracuse covers 25 square miles and had a population of approximately 145,170 in 2010. According to the Census, nearly one-quarter (23.3 percent) of the population was under the age of $18 ; 56$ percent of it was white, 29.5 percent, African American, 8.3 percent Hispanic or Latino, and 5.5 percent, Asian. The proportion of the city's population living in poverty ( 33.6 percent) was more than double that of the nation (15 percent).

Syracuse is not a big city, but it has big-city violence. Despite some decreases in the past several years, violent crime in Syracuse remains well above not only the average for cities its size (100,00o to 249,999) but even above the average for the largest U.S. cities. In 2011, the violent crime rate (per 100,000 population) in Syracuse was 892.9, 79 percent higher than the rate for cities of comparable size (498.5), and 27 percent higher than that of the largest U.S. cities. The rate of aggravated assaults that same year (576 per 100,000) was 94 percent higher than the rate in similarly sized cities, and 54 percent higher than that of the largest U.S. cities.

In 2007, the Syracuse Police Department had a sworn strength of 498 and an actual strength of 485, of whom 203 were uniformed and regularly assigned duties that included responsibility for responding to calls, with 16 assigned to community policing. Most (91.8 percent) of the sworn personnel were white, 7 percent were black, and 1 percent were Hispanic; 11.8 percent were female. The chief of police is appointed by and serves at the pleasure of the mayor. The chief who agreed to participate in this project was first appointed by a newly elected mayor in late 2009, and continues to serve at the time of this writing. The deputy chief of the Uniform Bureau oversees patrol, which is organized into three platoons, each commanded by a captain.

The community policing unit was part of the Community Services Bureau, which was commanded by a deputy chief. The department had a formal, written community-policing plan, though it did not encourage officers to conduct SARAguided problem-solving projects. Training in community policing was provided to all new officers through recruit training.

Syracuse has a Citizen Review Board, which was originally established in 1993, and which is authorized to "hear, investigate and review" complaints of police misconduct. ${ }^{3}$ The CRB has a full-time, paid administrator. The Internal Affairs (IA) Division of the police department conducts "initial investigations" (Cintron 2003,21 ), which are forwarded to the CRB for review. However, if the complainant so requests, the CRB is authorized to hold a full fact-finding hearing, which 
is conducted by a CRB panel of three members. The CRB was the subject of some controversy during the project, which we discuss below.

The department initiated Compstat (but spelled "Comstat") in 1999. Compstat had reportedly evolved over time, but had always been convened on a regular, biweekly basis. Compstat provides for presentations by platoon commanders and other unit commanders, as well as by a representative from the crime analysis unit. We further describe Syracuse's Compstat in chapter 8, but suffice to say here that, like Schenectady's, its operation resembles that of the departments studied by Willis et al. (2007).

By way of contrast with Schenectady's recent history at the outset of this project, the Syracuse Police Department appears to be fairly typical, insofar as the department received a share of bad press locally but nothing extraordinary. For example, in 2005 the then-chief resigned following his arrest for driving while intoxicated; the print media followed the troubles of one Syracuse officer who was involved in (and arrested for) giving cigarettes, marijuana, and alcohol to minors, drug trafficking out of his home, and sexually abusing two young boys. More commonly, the coverage of the Syracuse police focused on use of force that was alleged to be excessive.

During the project and while the police services survey was in progress, the Syracuse police were subject to further negative print media attention. One highvisibility source of bad press was a dispute between the department and the Onondaga County district attorney. A sexual abuse case against a well-known Syracuse University basketball coach received local and national media attention, and a conflict between the district attorney's office and the police department played out in the media, with the district attorney issuing a subpoena requiring the police to turn over the records of their investigation. The district attorney continued to publicly air his disagreements with the leadership of the department in what one local media outlet described as an "extraordinary public war of words with ... [the chief] for more than a year” (O’Brien and O'Hara 2013).

Tensions between the mayor's office and the department arose when the mayor refused to sign a commendation for an officer in 2010 because he was previously found to have used excessive force against a suspect in a drug and assault case. The mayor said that she has been working to clean out a minority of police officers whose behavior had been inappropriate: "[W]e are actively changing the culture and the behavior," she said (O'Brien 2010b). As a response, the police union and its members boycotted the city's annual awards ceremony in June and held their own in August.

The Citizen Review Board (CRB) was disbanded by the mayor and recreated. In February 2011, the mayor fired the CRB administrator because she "failed to do her job" (Knauss 2012). The CRB is an eleven-member panel, eight members of which are appointed by the Common Council and three by the mayor. The mayor 
appointed her three new members in January 2012 and the new administrator was announced in April that year. Although the chief of police supports the CRB, the police union sees it as "unnecessary" (Reiner 2012). The union particularly objected to the CRB's subpoena power, which requires a police officer to appear in front of the board's panel, but does not force the officer to speak. The union president said that the CRB did not have the proper training to investigate a police officer; the officers had twenty weeks' worth of training, he observed, and they (the CRB members) would not do twenty hours' worth (Reiner, 2012).

In addition to citizens' complaints about unfair treatment that filter into the media, officers' complaints about unfair treatment have also received coverage. In March 2010, a female officer was awarded $\$ 400,000$ in a sexual discrimination suit. She was reportedly the third officer in a ten-month period to receive a large award for sexual discrimination (O'Brien 2010a). Then, in February 2012, three black officers sued the department for racial discrimination, stating that they had been passed over for promotions and discriminated against by the police force and their own union because of their race (Eisenstadt 2012).

\section{Contrasts}

Some negative media attention is inevitable for a city police department, and we know of no well-established metric of bad press. Both of the study departments received some unfavorable attention in local media. But Schenectady's police had been the subject of extraordinary attention, not only in the form of uncomplimentary media coverage, but also in the form of a DOJ civil rights investigation, and even public speculation by the city's mayor about the wisdom of disbanding the department. Whether the unfavorable distinction that Schenectady police earned translated into a lower level of public trust is intuitively likely, though it is an empirical question. We supposed that if one of the two departments stood to enhance its legitimacy more through improvements in the procedural justice of police-citizen encounters, it was Schenectady's. But the two agencies were similar in many respects, and as the project began in 2011, the worst of Schenectady's scandals were behind it. We would do well to bear Schenectady's recent history in mind, but we can nevertheless think of the study of either department as a replication of the study of the other.

\section{SUMMARY}

When police departments are viewed as institutionalized organizations, we can better understand how it is that reforms, such as community policing or the procedural justice model, tend to come undone. Vats of ink have been spilt on the difficulties in organizational change, and police departments are no exceptions to the rule that organizations tend to resist change. Change in the form of the procedural 
justice model can be done in all executive sincerity and with the best of intentions through, say, pronouncements about the importance of legitimacy and how police treat citizens, changing procedures, ${ }^{5}$ or even rolling out a training curriculum, but we should be skeptical that these reforms will produce systematic changes in the department's technical core, in police-citizen interactions at the street level. Structures that are designed to be tightly coupled with day-to-day practice may, upon inspection, be no more than loosely coupled (or decoupled) from practice. To administrative exhortation we may anticipate rank-and-file resistance, the likes of which we will describe in more detail in chapter 9. If there are domains of police work that are susceptible to control through administrative rule-making, procedural justice is probably not one of them. Police departments cannot mandate procedurally just treatment, and even if they tried to do so, the mandate would be virtually unenforceable. Departments can prohibit some forms of procedural injustice, such as discourtesy, as many already do, though these prohibitions are (or have been) difficult to enforce. And in any event, police managers will need to make judgments about the extent to which they want to and should micro-manage their subordinates' behavior. Training can be (and in some instances, has been) delivered, but the lessons of training must be reconcilable with the (interpreted) requirements of the streets, and reinforced by supervisors, or its effects are likely to decay; that is, then, training must be tightly coupled with the day-to-day reality of officers' experience, and if it is not, it will prove ineffective.

With this institutional perspective as background, we proceed now to the findings of our empirical research in and with these departments. In chapter 3 we examine public trust and confidence in the police and police legitimacy, and then in chapters 4 and 5, citizens' subjective experience with police, and especially citizens' judgments about procedural justice. 